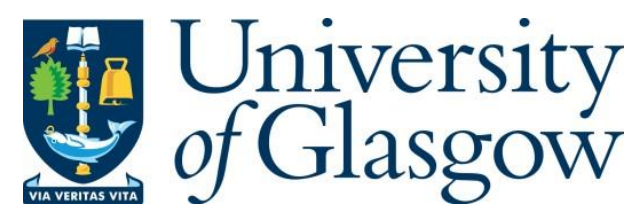

Saffian, S. M., Duffull, S. B., Roberts, R. L., Tait, R. C., Black, L., Lund, K. A., Thomson, A. H. and Wright, D. F.B. (2016) Influence of genotype on warfarin maintenance dose predictions produced using a Bayesian dose individualization tool. Therapeutic Drug Monitoring, 38(6), pp. 677-683.

There may be differences between this version and the published version. You are advised to consult the publisher's version if you wish to cite from it.

http://eprints.gla.ac.uk/227666/

Deposited on: 1 June 2021

Enlighten - Research publications by members of the University of Glasgow http://eprints.gla.ac.uk 


\section{The influence of genotype on warfarin maintenance dose predictions produced using a Bayesian dose individualisation tool}

Shamin M Saffian, BPharm, PgCertPharm ${ }^{1,2}$, Stephen B Duffull, $\mathrm{PhD}^{1}$, Rebecca L Roberts, $\mathrm{PhD}^{3}$, R Campbell Tait, $\mathrm{MBChB}^{4}$, Leanne Black, $\mathrm{MSc}^{5}$, Kirstin A Lund, $\mathrm{MBChB}^{4}$, Alison $\mathrm{H}$ Thomson, $\mathrm{PhD}^{5,6}$, Daniel F B Wright, $\mathrm{PhD}^{1}$

${ }^{1}$ School of Pharmacy, University of Otago, Dunedin, New Zealand

${ }^{2}$ Faculty of Pharmacy, Universiti Kebangsaan Malaysia, Malaysia

${ }^{3}$ Department of Surgical Sciences, University of Otago, Dunedin, New Zealand

${ }^{4}$ Department of Haematology, Royal Infirmary, Glasgow, Scotland

${ }^{5}$ Pharmacy Department, Glasgow Royal Infirmary, Glasgow, Scotland

${ }^{6}$ Strathclyde Institute of Pharmacy and Biomedical Sciences, University of Strathclyde, Glasgow, Scotland

\section{Corresponding author}

Shamin M Saffian

School of Pharmacy, University of Otago

PO Box 56, Dunedin 9054, New Zealand

Phone: +6434795045

Fax: +64 34797034

Email: shamin.mohdsaffian@otago.ac.nz

Running head: Predicting warfarin maintenance doses

Keywords: warfarin, INR, VKORC1, CYP2C9, Bayesian

Tables and figures: 4 tables, 2 figures.

Abstract character count: 1985

Manuscript word count: 2808

Conflicts of Interest

The authors declare no conflict of interest

Source of Funding

No financial aid was used in this work

This is a peer-reviewed accepted author manuscript of the following article: Thomson, A., Duffull, S., Wright, D., Saffian, S., Roberts, R., Tait, C., ... Lund, K. (2016). The influence of genotype on warfarin maintenance dose predictions produced using a Bayesian dose individualization tool. Therapeutic Drug Monitoring. DOI: 10.1097/FTD.0000000000000347 


\section{Background}

A previously established Bayesian dosing tool for warfarin was found to produce biased maintenance dose predictions. In the following study we aimed to: (1) determine if the biased warfarin dose predictions previously observed could be replicated in a new cohort of patients from two different clinical settings; (2) explore the influence of CYP2C9 and VKORC1 genotype on the predictive performance of the Bayesian dosing tool; and (3) determine if the prior population used to develop the kinetic-pharmacodynamic (KPD) model underpinning the Bayesian dosing tool was sufficiently different from the test (posterior) population to account for the biased dose predictions.

\section{Methods}

The warfarin maintenance doses for 140 patients were predicted using the dosing tool and compared to the observed maintenance dose. The impact of genotype was assessed by predicting maintenance doses with prior parameter values known to be altered by genetic variability (e.g. $\mathrm{EC}_{50}$ for VKORC1 genotype). The prior population was evaluated by fitting the published kinetic-pharmacodynamic model, which underpins the Bayesian tool, to the observed data using NONMEM and comparing the model parameter estimates to published values.

\section{Results}

The Bayesian tool produced positively biased dose predictions in the new cohort of patients (mean prediction error $[95 \% \mathrm{CI}] ; 0.32 \mathrm{mg} / \mathrm{day}[0.14,0.5])$. The bias was only observed in patients requiring $\geq 7 \mathrm{mg} / \mathrm{day}$. The direction and magnitude of the observed bias was not influenced by genotype. The prior model provided a good fit to our data, suggesting that the bias was not caused by different prior and posterior populations.

\section{Conclusions}

Maintenance doses for patients requiring $\geq 7 \mathrm{mg} /$ day were over-predicted. The bias was not due to the influence of genotype nor was it related to differences between the prior and posterior populations. There is a need for a more mechanistic model that captures warfarin dose-response relationship at higher warfarin doses. 


\section{INTRODUCTION}

Warfarin is an anticoagulant used to treat and prevent blood clots in patients with deep vein thrombosis, pulmonary embolism and atrial fibrillation. It is a difficult drug to dose accurately and safely due to a narrow therapeutic range and a delay in the time course of anticoagulant response relative to dosing. Furthermore, the maintenance dose required to achieve therapeutic anticoagulation varies by upwards of 15 fold between patients. ${ }^{1,2}$ Anticoagulation is monitored during warfarin therapy using the international normalised ratio (INR). The target INR for most indications, including atrial fibrillation, is approximately 2.5 with a suggested therapeutic range of 2-3. Treatment is considered successful if the time that patients spend within the therapeutic range (TTR) is maximised. Conventional, heuristic, dosing methods have been found to result in a TTR of only $40-60 \%{ }^{3-6}$

There have been a large number of publications exploring strategies to improve INR control and to predict warfarin dose requirements. A variety of nomograms, computerised decision-support tools and Bayesian prediction tools have been proposed to aid dosing decisions in the clinic. ${ }^{7-10}$ In the past ten years, more than 30 warfarin dosing algorithms have been published. ${ }^{11,12}$ These algorithms are developed by regressing patient characteristics, including age, body size, ethnicity, concomitant drug use and genetic variability in warfarin metabolism (via the cytochrome $\mathrm{P}-450$ enzyme CYP2C9 ) or vitamin $\mathrm{K}$ recycling (via vitamin $\mathrm{K}$ epoxide reductase, $V K O R C 1)^{1,12-14}$, against maintenance dose requirements. The algorithms therefore provide a means of rapidly predicting warfarin dosing requirements prior to the initiation of therapy. ${ }^{1,13,15,16}$ To date however, clinical trials have not consistently demonstrated that dose prediction using warfarin algorithms improves anticoagulant control or patient outcomes compared to other methods. ${ }^{17-23}$ For this reason, neither the American College of Chest Physicians $(\mathrm{ACCP})^{24}$ nor the British Committee for Standards in Haematology $(\mathrm{BCSH})^{25}$ consensus guideline advocate the use of dose prediction tools or genotyping prior to the initiation of therapy.

Bayesian forecasting methods for warfarin may provide a means of improving INR control without prior knowledge of CYP2C9 or VKORC1 genotype. ${ }^{26}$ In limited studies to date, Bayesian methods show the potential to increase the TTR to $80 \%$ or more. ${ }^{26-29}$ In addition, Bayesian algorithms can easily be integrated with decision support tools for use in the clinic (see Hamberg et al. $2015^{30}$ for an example).

We have shown previously that a Bayesian forecasting method can produce unbiased warfarin maintenance dose predictions on average. ${ }^{11,26}$ However, in a post-hoc analysis we found that doses for patients with VKORC1 ($1639 \mathrm{G}>$ A) GG genotype were positively biased by about $1 \mathrm{mg}$ /day on average, suggesting a possible influence of genotype on predictive performance. Of note, this effect was evident only in those patients taking doses greater 
than about $7 \mathrm{mg}$ daily. In the following study we aimed to: (1) determine if the previously observed biased warfarin dose predictions could be replicated in a new cohort of patients from two different clinical settings; (2) explore the influence of $C Y P 2 C 9$ and $V K O R C 1$ genotype on the predictive performance of the Bayesian dosing tool; and (3) determine if the prior population used to develop the kinetic-pharmacodynamic (KPD) model underpinning the Bayesian dosing tool was sufficiently different from the test (posterior) population to account for the biased dose predictions.

\section{METHODS}

\section{Patient data}

The data consisted of warfarin dose and INR values from patients initiating warfarin therapy for any indication. INR values were recorded from the start of therapy until a stable INR had been achieved. A stable INR was defined as the second INR within $20 \%$ of the INR target (2.5 in most cases) as described elsewhere. ${ }^{11}$ Patients were genotyped for VKORC1 (-1639 G>A rs9923231) and CYP2C9*1, *2 (430C $>\mathrm{T}$, rs 1799853) and *3 $(1075 \mathrm{~A}>\mathrm{C}$, rs 1057910) as described elsewhere. ${ }^{11,31}$ Ethical approval was obtained from the Lower South Regional Ethics Committee, New Zealand (LRS/10/11/056) and West of Scotland Research Ethics Service, Glasgow, Scotland. All participating patients gave written informed consent.

Data from a total of 153 patients were available for analysis and came from two centers;

i. $\quad$ Dataset I - Dunedin Hospital, Dunedin, New Zealand ${ }^{11}(\mathrm{n}=55)$

ii. Dataset II - Glasgow Royal Infirmary, Glasgow, Scotland ${ }^{32}(\mathrm{n}=98)$

\section{Maintenance dose predictions}

Details of the development of the Bayesian dosing tool (TCIWorks) have been published previously. ${ }^{33}$ The underpinning model that describes the warfarin dose and anticoagulant response was a KPD model developed by Hamberg et al. ${ }^{34}$ Briefly, a KPD model is a pharmacokinetic-pharmacodynamic model where the pharmacokinetic parameters are estimated solely from the pharmacodynamic data. This means that no warfarin concentration data are required to predict the INR response. The KPD model developed by Hamberg et $\mathrm{al}^{30}$ consists of two transit compartment chains with three compartments in each chain to describe the time course of INR response. An Emax model was used to describe the link between pharmacokinetics and pharmacodynamics. The KPD model also included a covariate model for VKORC1 on EC50 (concentration of s-warfarin at $50 \%$ of maximum drug effect) 
and age and CYP2C9 on clearance parameters, however, genotype was not included as a covariate in the Bayesian dosing tool (see Wright and Duffull ${ }^{33}$ for details).

The full dosing history for each patient from initiation to a stable INR, age, and all available INR observations up to the final dose change were entered into the Bayesian dosing tool. The Bayesian dosing tool was then used to predict the daily dose required to achieve the observed stable INR for each patient. The patients were assumed to be taking their prescribed dose at $6 \mathrm{pm}$ and INR was assumed to be sampled at $10 \mathrm{am}$. The effects of concomitant drugs on warfarin INR response would be captured by the INR measurement itself and therefore was not accounted for a priori.

\section{The predictive performance of the Bayesian dosing tool}

The predicted maintenance doses were compared to the observed maintenance doses using measures of bias (mean prediction error $[M P E]$ ) and mean squared error $[M S E]$ or root mean squared error $[R M S E]$. MPE, $M S E$, and $R M S E$ were calculated as follows:

$$
\begin{aligned}
& M P E=\frac{1}{N} \sum_{i=1}^{N} P E_{i}, \\
& M S E=\frac{1}{N} \sum_{i=1}^{N}\left(P E_{i}\right)^{2}, \\
& R M S E=\sqrt{M S E},
\end{aligned}
$$

where $M P E$ is the mean prediction error, $N$ is the number of patients, $P E_{i}$ is the prediction error (predicted minus observed maintenance dose) of the $i^{\text {th }}$ individual. No statistical bias was concluded if the $95 \%$ confidence interval (CI) of the $M P E$ included zero. $M S E$ is the average of the sum of squared differences between predicted minus observed maintenance dose, and RMSE is the square root of MSE. RMSE provides an estimate of the variability of the prediction errors given in approximately the same units of the data (mg/day).

We stratified the dataset by observed maintenance dose into two groups; those who required $\geq 7 \mathrm{mg} / \mathrm{day}$ and those who required $<7 \mathrm{mg} /$ day. A cut off of $7 \mathrm{mg} /$ day has been used in other studies ${ }^{1,35}$ to categorize patients requiring a "high" daily dose and therefore was used here. $M P E$ and $R M S E$ were assessed as above for each dose group.

\section{The impact of genotype on the predictive performance of the Bayesian dosing tool}

The influence of genotype on warfarin dose predictions was assessed by stratifying the study cohort into different VKORC1 and CYP2C9 genotypes and measuring MPE and RMSE, as above, for each genotype group. 
We also tested the influence of VKORC1 genotype on Bayesian dose predictions by altering the mean prior parameter values of $\mathrm{EC}_{50}$ to reflect the observed genotype in each patient. This is intended as a diagnostic aid to understand a possible source of bias and not how the Bayesian tool would normally be used. The prior parameter values was normally set to the wild-type (GG) value for all patients. For the purposes of this analysis the mean $\mathrm{EC}_{50}$ was changed manually for each patient prior to predicting the maintenance dose. The parameter values chosen corresponded to the observed genotype effect reported in the published model by Hamberg et al ${ }^{34}$, i.e. an $\mathrm{EC}_{50}$ of $4.01 \mathrm{mg} / \mathrm{L}$ for those with $V K O R C 1 \mathrm{GG}$ genotype, $3.01 \mathrm{mg} / \mathrm{L}$ for individuals with $V K O R C 1$ GA genotype, and $1.92 \mathrm{mg} / \mathrm{L}$ for the $V K O R C 1$ AA genotype. The initial parameter estimates of $C Y P 2 C 9$ were set to the wildtype $(* 1 * 1)$ and only tested further if there was any significant improvement in bias was observed by changing the $V K O R C 1$ prior parameter estimates.

\section{The impact of the prior population on predictive performance of the Bayesian dosing tool}

We explored the hypothesis that the bias may be caused by inherent differences in warfarin dose-response within our study population compared to the population used to develop the KPD model by Hamberg et al. ${ }^{34}$ To address this, we fitted the published KPD model to our dataset using a nonlinear mixed effects modelling methodology in NONMEM (version 7.2 (Icon Inc. [PA, USA]). Initial parameter estimates were the values reported by Hamberg et al. ${ }^{34}$ A non-parametric bootstrap was carried out to assess the precision of the parameter estimates. A total of 1000 bootstrap datasets were generated by randomly sampling the original dataset and simulated from the model to obtain the $95 \%$ CI of each parameter estimate. The mean and $95 \%$ CI of the estimated model parameters from our study cohort were compared to the values from the published KPD model and considered not significantly different if the means were within $20 \%$ of the published values and confidence intervals overlapped with the published $95 \%$ CI.

\section{RESULTS}

Thirteen of the original 153 patients were excluded from the analysis; 12 who were not genotyped and 1 who did not reach a stable INR. The demographic details of the remaining 140 patients are summarised in Table 1 . The distributions of both genotypes were consistent with the Hardy-Weinberg equilibrium $(\mathrm{p}>0.05)$. Median (range) age was 62 years (23-87) and 65 years (15-85) for datasets I and II, respectively.

\section{The predictive performance of the Bayesian dosing tool}

A summary of the MPE and RMSE results for each dataset analyzed separately and combined is presented in Table 2. The Bayesian dosing tool, on average, produced positively biased dose predictions (MPE mg/day [95\% 
$\mathrm{CI}] ; 0.32[0.14,0.50])$. When analysed separately, dose predictions for both the Dunedin (dataset I) and Glasgow datasets (dataset II) were also both positively biased (MPE mg/day [95\% CI]; $0.53[0.11,0.94]$ and 0.22 [0.04, 0.39 ] respectively).

The average prediction error for patients requiring $\geq 7 \mathrm{mg}$ /day was $+1.15 \mathrm{mg} /$ day which represents an average over-prediction of approximately $18 \%$, while the average prediction error for patients requiring $<7 \mathrm{mg} / \mathrm{day}$ was $+0.18 \mathrm{mg}$ /day. $R M S E$ values for patients requiring $<7 \mathrm{mg} /$ day and $\geq 7 \mathrm{mg} /$ day were $0.94 \mathrm{mg} /$ day and $1.90 \mathrm{mg} / \mathrm{day}$, respectively.

\section{The impact of genotype on the predictive performance of the Bayesian dosing tool}

Dose predictions for patients with the VKORC1 GG genotype were found to be positively biased but dose predictions for patients with $V K O R C 1 \mathrm{AG}$ and AA were unbiased (see Table 2). Similarly, dose predictions for patients with $C Y P 2 C 9 * 1 * 1$ were positively biased in the combined dataset.

To explore the influence of genotype further, we compared the MPE for patients with VKORC1 GG genotype who had $C Y P 2 C 9 * 1 * 1$ and those who were not $C Y P 2 C 9 * 1 * 1$ and found a positive bias for both combinations. However, when we grouped patients with CYP2C $9 * 1 * 1$ patients who were not VKORC1 GG, we found that dose predictions were not biased. This suggests that the source of the bias is more likely to be VKORC1 genotype.

Visual plots of the observed versus prediction maintenance dose according to $V K O R C 1$ and $C Y P 2 C 9$ are presented in Figures 1 and 2, respectively.

The Bayesian dose predictions conducted using individual values of $\mathrm{EC}_{50}$ for each patient, corresponding to their observed genotype, were found to produce positively biased results overall (see Table 3). It is noteworthy that those subjects with reduced $\mathrm{EC}_{50}$ values (i.e. VKORC1 AG and AA genotypes) had unbiased dose predictions. The MPE for the VKORC1 GG genotype group remained the same since the wild-type values were used previously.

\section{The impact of the prior population on the predictive performance of the Bayesian dosing tool}

The results of the estimated parameters and bootstrap runs using the model to estimate into a new population are summarized in Table 4. 93.8\% of the bootstrap runs minimized successfully. Several mean parameter estimates were above the $20 \%$ criterion, however, mean parameter estimates for the more important parameters, such as $\mathrm{EC}_{50}$ for $\mathrm{G}$ allele and $\mathrm{EC}_{50}$ for $\mathrm{A}$ allele and between subject variability for $\mathrm{EC}_{50}$, were within $20 \%$. The $95 \% \mathrm{CI}$ for 
all the parameters estimated from the test population overlapped with the published model, except the population value for MTT1 (mean transit time). This parameter is not considered likely to be a cause of bias in predictions.

\section{DISCUSSION}

In this study, we have explored the possible causes of bias in warfarin maintenance dose predictions with a Bayesian dosing tool. A previously reported over-prediction of warfarin maintenance dose requirements was successfully replicated using two datasets from different clinical centres. Furthermore, dose predictions were carried out in the Bayesian system using all available INR measurements for each patient which should provide the most accurate estimate of the patient's response. The biased warfarin dose predictions were only observed in patients requiring $\geq 7 \mathrm{mg} /$ day.

Several publications on the application of Bayesian methodologies to warfarin dose individualisation have been reported previously. ${ }^{9}, 10,27,36-38$ A summary of previous Bayesian dosing tools for warfarin and how they differ from the dosing tool in our study have also been reviewed. ${ }^{26,33}$ Vadher et $\mathrm{al}^{9}$ compared the observed dose to the predicted maintenance dose and found that their Bayesian dosing tool was negatively biased on average. A scatter plot of the observed dose versus predicted dose reported by Vadher et $\mathrm{al}^{9}$ also showed biased predictions in patients requiring higher daily doses, although in a different direction (under-prediction in higher dose patients). Other publications on Bayesian dosing tools for warfarin did not analyse the predictive performance of the dosing tool in a way that would allow comparison with our work.

Two possible explanations for the bias were explored in this study. First, we explored the hypothesis that the bias may be due to the influence of $V K O R C 1$ or $C Y P 2 C 9$ genotype. We focused primarily on $V K O R C 1$ since it was identified as a candidate in previous work ${ }^{11}$ but in the present study it was found to have a relatively minor influence on dose predictions. In addition, the direction of dose prediction error (i.e. over or under-predicted dose) in each patient requiring $\geq 7 \mathrm{mg} /$ day was the same despite changing the $\mathrm{EC}_{50}$ priors to the values as per published prior model. This suggests that differences in $\mathrm{EC}_{50}$ prior parameter estimates (and hence influence of $V K O R C 1$ ) does not have significant influence on the overall dose predictions and therefore does not explain the observed bias. Furthermore, the initial apparent association of bias and VKORC1 GG may be explained by a higher proportion of patients with $V K O R C 1$ GG in this dose category and therefore, the initial link between $V K O R C 1$ GG and bias was more likely to be an association rather than a cause. We also explored the possibility that the population used to derive the prior population parameter estimate for the KPD model had a different dose-response 
to our study population which would mean that the model could not be extrapolated to our study population. Our results suggest that the prior and posterior populations were not sufficiently different to be a plausible cause of the observed bias.

As noted above, the bias in warfarin dose predictions was evident only for those patients taking $\geq 7 \mathrm{mg} / \mathrm{day}$. The reason for this is not currently clear. Since we have found that it is not likely to be the parameter values used as the basis of the prior, then this suggests it could be the structure of the prior model. We know the coagulation network is exceedingly complex. ${ }^{39}$ We therefore feel it is plausible that the application of a single $\mathrm{E}_{\max }$ model when used across a large range of dose-response values (as seen here) may not be sufficiently flexible to account for the inherent feedback and feedforward mechanisms of the coagulation network, which may be more apparent in those patients taking higher than average warfarin doses. A further exploration of this hypothesis is beyond the scope of the current work.

Although an accurate method for predicting the maintenance dose of warfarin intuitively should improve clinical outcomes, this can only be proven in clinical trials. Importantly, whether the observed bias in warfarin dose predictions might result in altered clinical outcomes cannot be explored in this study. Exploring a non-parametric approach to population modelling and Bayesian forecasting was beyond the scope of the current study.

\section{CONCLUSION}

In two patient cohorts, the Bayesian dosing tool resulted in positively biased warfarin dose predictions. Warfarin doses were over-predicted for patients requiring $\geq 7 \mathrm{mg} /$ day by $1.15 \mathrm{mg} /$ day on average. The bias was not found to be due to the influence of $V K O R C 1$ genotype, nor to differences in the prior and posterior populations. We conclude that there is a need for a more mechanistic dose-response model for warfarin that is capable of capturing the complexities of the coagulation network at higher warfarin doses.

\section{Acknowledgements}

The authors wish to thank to Mr Lionel van den Berg and Professor Carl Kirkpatrick from Monash University for their invaluable assistance with the Bayesian dosing tool, TCIWorks. At the time of writing, Shamin Saffian was a recipient of a Malaysian Government Scholarship. 


\section{References}

1. Klein T, Altman R, Eriksson N, et al. Estimation of the warfarin dose with clinical and pharmacogenetic data. $N$ Engl J Med. 2009;360:753-764.

2. Voora D, Koboldt DC, King CR, et al. A polymorphism in the $V K O R C 1$ regulator calumenin predicts higher warfarin dose requirements in African Americans. Clin Pharmacol Ther. 2010;87:445- 451.

3. Chiquette E, Amato MG and Bussey HI. Comparison of an anticoagulation clinic with usual medical care: Anticoagulation control, patient outcomes, and health care costs. Arch Intern Med. 1998;158:1641-1647.

4. Matchar DB, Jacobson A, Dolor R, et al. Effect of home testing of international normalized ratio on clinical events. N Engl J Med. 2010;363:1608-1620.

5. van Walraven C, Jennings A, Oake N, et al. Effect of study setting on anticoagulation control: A systematic review and metaregression. Chest. 2006;129:1155-1166.

6. Witt DM, Sadler MA, Shanahan RL, et al. Effect of a centralized clinical pharmacy anticoagulation service on the outcomes of anticoagulation therapy. Chest. 2005;127:1515-1522.

7. Tait RC and Sefcick AA. warfarin induction regimen for out-patient anticoagulation in patients with atrial fibrillation. Br J Haematol. 1998;101:450-454.

8. Fennerty A, Dolben J, Thomas P, et al. Flexible induction dose regimen for warfarin and prediction of maintenance dose. British medical journal (Clinical research ed). 1984;288:1268-1270.

9. Vadher B, Patterson D and Leaning M. Prediction of the international normalized ratio and maintenance dose during the initiation of warfarin therapy. Br J Clin Pharmacol. 1999;48:63.

10. Boyle DA, Ludden TM, Carter BL, et al. Evaluation of a Bayesian regression program for predicting warfarin response. Ther Drug Monit. 1989;11:276-284.

11. Saffian SM, Wright DF, Roberts RL, et al. Methods for Predicting Warfarin Dose Requirements. Ther Drug Monit. 2015;37:531-538

12. Verhoef TI, Redekop WK, Daly AK, et al. Pharmacogenetic-guided dosing of coumarin anticoagulants: algorithms for warfarin, acenocoumarol and phenprocoumon. Br J Clin Pharmacol. 2014;77:626-641.

13. Gage BF, Eby C, Johnson JA, et al. Use of pharmacogenetic and clinical factors to predict the therapeutic dose of warfarin. Clin Pharmacol Ther. 2008;84:326-331.

14. Lenzini P, Wadelius M, Kimmel S, et al. Integration of genetic, clinical, and INR data to refine warfarin dosing Clin Pharmacol Ther. 2010;87:572-578.

15. Kim YK, Nieuwlaat R, Connolly SJ, et al. Effect of a simple two-step warfarin dosing algorithm on anticoagulant control as measured by time in therapeutic range: A pilot study $J$ Thromb Haemost. 2010;8:101-106.

16. Sconce EA, Khan TI, Wynne HA, et al. The impact of CYP2C9 and VKORC1 genetic polymorphism and patient characteristics upon warfarin dose requirements: Proposal for a new dosing regimen. Blood. 2005;106:2329-2333

17. Anderson JL, Horne BD, Stevens SM, et al. Randomized trial of genotype-guided versus standard warfarin dosing in patients initiating oral anticoagulation. Circulation. 2007;116:2563-2570.

18. Burmester JK, Berg RL, Yale SH, et al. A randomized controlled trial of genotype-based Coumadin initiation. Genet Med. 2011;13:509-518.

19. Caraco Y, Blotnick S and Muszkat M. CYP2C9 genotype-guided warfarin prescribing enhances the efficacy and safety of anticoagulation: A prospective randomized controlled study. Clin Pharmacol Ther. 2008;83:460-470.

20. Hillman MA, Wilke RA, Yale SH, et al. A prospective, randomized pilot trial of model-based warfarin dose initiation using CYP2C9 genotype and clinical data. Clin Med Res. 2005;3:137-145.

21. Jonas DE, Evans JP, McLeod HL, et al. Impact of genotype-guided dosing on anticoagulation visits for adults starting warfarin: a randomized controlled trial. Pharmacogenomics. 2013;14:1593-1603.

22. Kimmel SE, French B, Kasner SE, et al. A Pharmacogenetic versus a Clinical Algorithm for Warfarin Dosing. N Engl J Med. 2013;369:2283-2293.

23. Pirmohamed M, Burnside G, Eriksson N, et al. A randomized trial of genotype-guided dosing of warfarin. N Engl J Med. 2013;369:2294-2303.

24. Holbrook A, Schulman S, Witt DM, et al. Evidence-based management of anticoagulant therapy: Antithrombotic Therapy and Prevention of Thrombosis, 9th ed: American College of Chest Physicians Evidence-Based Clinical Practice Guidelines. Chest. 2012;141:e152S-184S.

25. Keeling DM, Baglin T, Tait C, et al. Guidelines on oral anticoagulation with warfarin - fourth edition. $\mathrm{Br} J$ Haematol. 2011;154:311-324.

26. Wright DFB and Duffull SB A bayesian dose-individualization method for warfarin. Clin Pharmacokinet. 2013;52:59-68.

27. Motykie GD, Mokhtee D, Zebala LP, et al. The use of a Bayesian forecasting model in the management of warfarin therapy after total hip arthroplasty. J Arthroplasty. 1999;14:988-993. 
28. White RH, Hong R, Venook AP, et al. Initiation of warfarin therapy: comparison of physician dosing with computer-assisted dosing. J Gen Intern Med. 1987;2:141-148.

29. Harper P, Harper J and Hill C. An audit of anticoagulant management to assess anticoagulant control using decision support software. BMJ Open. 2014;4.

30. Hamberg AK, Hellman J, Dahlberg J, et al. A Bayesian decision support tool for efficient dose individualization of warfarin in adults and children. BMC Med Inform Decis Mak. 2015;15.

31. Lund K, Gaffney D, Spooner R, et al. Polymorphisms in VKORC1 have more impact than CYP2C9 polymorphisms on early warfarin International Normalized Ratio control and bleeding rates Br J Haematol. 2012;158:256-261.

32. Black L, Wright DFB, Thomson AH, et al. Bayesian forecasting: can TCIWorks accurately predict INR response to warfarin dosing?. The UK Clinical Pharmacy Association National Conference. Manchester, UK, 2014.

33. Wright DFB and Duffull SB. Development of a bayesian forecasting method for warfarin dose individualisation. Pharm Res. 2011;28:1100-1111.

34. Hamberg AK, Wadelius M, Lindh JD, et al. A pharmacometric model describing the relationship between warfarin dose and INR response with respect to variations in CYP2C9, VKORC1, and age. Clin Pharmacol Ther. 2010;87:727-734.

35. Finkelman BS, Gage BF, Johnson JA, et al. Genetic warfarin dosing: Tables versus algorithms. J Am Coll Cardiol. 2011;57:612-618.

36. Pitsiu M, Parker EM, Aarons L, et al. A Bayesian method based on clotting factor activity for the prediction of maintenance warfarin dosage regimens. Ther Drug Monit. 2003;25:36-40.

37. Svec JM, Coleman RW, Mungall DR, et al. Bayesian pharmacokinetic/pharmacodynamic forecasting of prothrombin response to warfarin therapy: Preliminary evaluation. Ther Drug Monit. 1985;7:174-180.

38. White RH and Mungall D. Outpatient management of warfarin therapy: comparison of computer-predicted dosage adjustment to skilled professional care. Ther Drug Monit. 1991;13:46-50.

39. Wajima T, Isbister GK and Duffull SB. A comprehensive model for the humoral coagulation network in humans. Clin Pharmacol Ther. 2009;86:290-298. 
Fig. 1 Scatter plot of the observed versus predicted maintenance dose according to VKORC1(-1639 G>A, rs9923231). The solid line is a line of identity. Filled symbols represent dataset I (Dunedin, New Zealand) and open symbols represent dataset II (Glasgow, Scotland)

Fig. 2 Scatter plot of the observed versus predicted maintenance dose for patients according to CYP2C9. The solid line is a line of identity. Filled symbols represent dataset I (Dunedin, New Zealand) and open symbols represent dataset II (Glasgow, Scotland) 
Table 1

Patient characteristics and a summary of maintenance dose and stable INR

\begin{tabular}{|c|c|c|c|}
\hline & $\begin{array}{l}\text { Dataset I } \\
(\mathrm{n}=46)\end{array}$ & $\begin{array}{l}\text { Dataset II } \\
(\mathrm{n}=94)\end{array}$ & $\begin{array}{c}\text { Combined dataset } \\
(\mathrm{n}=140)\end{array}$ \\
\hline Age (years) & $62(23-87)$ & $65(15-85)$ & $64(15-87)$ \\
\hline Male/Female (number of patients) & $19 / 27$ & $48 / 46$ & $67 / 73$ \\
\hline Time to reach first stable INR (days) & $38(11-118)$ & $24(9-64)$ & $28(9-118)$ \\
\hline $\begin{array}{l}\text { Number of INR observations to reach } \\
\text { stable INR }\end{array}$ & $11(6-21)$ & $9(6-24)$ & $10(6-24)$ \\
\hline Stable INR value & $2.4(2-3.1)$ & $2.3(2-3)$ & $2.4(2-3.1)$ \\
\hline Dose at stable INR (mg/day) & $5(1.5-11)$ & $4(0.75-10)$ & $4.5(0.75-11)$ \\
\hline Interquartile range [Q1 - Q3] & {$[4-7]$} & {$[3-5.4]$} & {$[3-5.57]$} \\
\hline \multicolumn{4}{|l|}{$\begin{array}{l}\text { CYP2C9 genotype } \\
\text { (number }(\%) \text { of patients) }\end{array}$} \\
\hline$* 1 * 1$ & $28(61 \%)$ & $60(64 \%)$ & $88(63 \%)$ \\
\hline$* 1 * 2$ & $8(17 \%)$ & $19(20 \%)$ & $27(19 \%)$ \\
\hline$* 1 * 3$ & $9(20 \%)$ & $10(11 \%)$ & $19(14 \%)$ \\
\hline$* 2 * 2$ & - & $2(2 \%)$ & $2(1 \%)$ \\
\hline$* 2 * 3$ & - & $2(2 \%)$ & $2(1 \%)$ \\
\hline$* 3 * 3$ & $1(2 \%)$ & $1(1 \%)$ & $2(1 \%)$ \\
\hline \multicolumn{4}{|l|}{$\begin{array}{l}\text { VKORC1 (-1639 G>A, rs9923231) } \\
\text { genotype (number (\%) of patients) }\end{array}$} \\
\hline GG & $23(50 \%)$ & $45(48 \%)$ & $68(49 \%)$ \\
\hline $\mathrm{AG}$ & $18(39 \%)$ & $38(40 \%)$ & $56(40 \%)$ \\
\hline $\mathrm{AA}$ & $5(11 \%)$ & $11(12 \%)$ & $16(11 \%)$ \\
\hline
\end{tabular}

Values are expressed as median (range) unless specified otherwise

Dataset I = Dunedin, New Zealand

Dataset II = Glasgow, Scotland 
Table 2

A summary of average bias (mean prediction error (95\% CI lower, upper) and root mean squared error of the dose predictions according to genotype.

\begin{tabular}{|c|c|c|c|c|c|c|c|c|c|c|c|}
\hline & & \multirow{2}{*}{$\begin{array}{c}\text { All } \\
\text { genotypes }\end{array}$} & \multicolumn{3}{|c|}{ VKORC1 } & \multicolumn{6}{|c|}{ СУР2C9 } \\
\hline & & & GG & $\mathrm{AG}$ & AA & $* 1 * 1$ & $* 1 * 2$ & $* 1 * 3$ & $* 2 * 2$ & $* 2 * 3$ & $* 3 * 3$ \\
\hline \multirow[t]{2}{*}{$\begin{array}{l}\text { Dataset I } \\
(n=46)\end{array}$} & $\begin{array}{c}M P E \\
(95 \% \mathrm{CI})\end{array}$ & $\begin{array}{c}0.53 \\
(0.11,0.94)\end{array}$ & $\begin{array}{c}1.13 \\
(0.48,1.77)\end{array}$ & $\begin{array}{c}-0.05 \\
(-0.67,0.56)\end{array}$ & $\begin{array}{c}-0.13 \\
(-0.68,0.43)\end{array}$ & $\begin{array}{c}0.46 \\
(-0.13,1.05)\end{array}$ & $\begin{array}{c}1.06 \\
(-0.43,2.56)\end{array}$ & $\begin{array}{c}0.29 \\
(-0.35,0.93)\end{array}$ & - & - & $\begin{array}{c}0.4 \\
(\mathrm{NA})\end{array}$ \\
\hline & $R M S E$ & 1.52 & 1.85 & 1.21 & 0.42 & 1.56 & 1.98 & 0.83 & - & - & 0.40 \\
\hline \multirow[t]{2}{*}{$\begin{array}{l}\text { Dataset II } \\
(\mathrm{n}=94)\end{array}$} & $\begin{array}{c}M P E \\
(95 \% \mathrm{CI})\end{array}$ & $\begin{array}{c}0.22 \\
(0.04,0.39)\end{array}$ & $\begin{array}{c}0.23 \\
(-0.05,0.52)\end{array}$ & $\begin{array}{c}0.23 \\
(-0.03,0.5)\end{array}$ & $\begin{array}{c}0.08 \\
(-0.37,0.54)\end{array}$ & $\begin{array}{c}0.32 \\
(0.07,0.57)\end{array}$ & $\begin{array}{c}-0.1 \\
(-0.37,1.7)\end{array}$ & $\begin{array}{c}0.29 \\
(-0.21,0.79)\end{array}$ & $\begin{array}{c}0.25 \\
\text { (NA) }\end{array}$ & $\begin{array}{l}-0.18 \\
\text { (NA) }\end{array}$ & $\begin{array}{c}0 \\
(\mathrm{NA})\end{array}$ \\
\hline & $R M S E$ & 0.88 & 0.97 & 0.84 & 0.65 & 1.00 & 0.55 & 0.72 & 0.79 & 0.80 & 0.00 \\
\hline \multirow[t]{2}{*}{$\begin{array}{l}\text { Combined } \\
\text { dataset }\end{array}$} & $\begin{array}{c}M P E \\
(95 \% \mathrm{CI})\end{array}$ & $\begin{array}{c}0.32 \\
(0.14,0.5)\end{array}$ & $\begin{array}{c}0.53 \\
(0.21,0.86)\end{array}$ & $\begin{array}{c}0.14 \\
(-0.11,0.4)\end{array}$ & $\begin{array}{c}0.02 \\
(-0.28,0.32)\end{array}$ & $\begin{array}{c}0.36 \\
(0.12,0.61)\end{array}$ & $\begin{array}{c}0.24 \\
(-0.22,0.71)\end{array}$ & $\begin{array}{c}0.29 \\
(-0.07,0.65)\end{array}$ & $\begin{array}{c}-0.5 \\
(-9.3,9.8)\end{array}$ & $\begin{array}{c}-0.18 \\
(-10,9.7)\end{array}$ & $\begin{array}{c}0.39 \\
(-2.3,2.7)\end{array}$ \\
\hline & $R M S E$ & 1.13 & 1.34 & 0.97 & 0.59 & 1.21 & 1.17 & 0.78 & 0.79 & 0.80 & 0.28 \\
\hline
\end{tabular}

$M P E$ mean prediction error (mg/day), CI confidence interval, $R M S E$ root mean squared error (mg/day), Dataset I = Dunedin, New Zealand, Dataset II = Glasgow, Scotland, NA not available. 


\section{Table 3}

2 A summary of mean prediction error (MPE) and root mean squared error (RMSE) using the individual's 3 genotype to determine the prior value of $\mathrm{EC}_{50}$ used in the population model

4

\begin{tabular}{lcc}
\hline $\begin{array}{l}\text { VKORC1 }(-1639 \mathrm{G}>\mathrm{A}) \\
\text { genotype }\end{array}$ & MPE (mg/day) & RMSE \\
\hline All data & $0.28(0.09,0.46)$ & 1.14 \\
GG & $0.53(0.21,0.86)$ & 1.34 \\
AG & $0.08(-0.18,0.35)$ & 1.01 \\
AA & $-0.11(-0.46,0.23)$ & 0.65 \\
\hline
\end{tabular}

5

6 


\section{Table 4}

9 Parameter estimates from the published prior kinetic-pharmacodynamic (KPD) model (as a comparison) and 10 bootstrap resampling

\begin{tabular}{|c|c|c|}
\hline Parameter & $\begin{array}{r}\text { Published prior KPD model } \\
{[95 \% \mathrm{CI}]}\end{array}$ & $\begin{array}{r}\text { Bootstrap mean estimate } \\
{[95 \% \mathrm{CI}]}\end{array}$ \\
\hline$E C_{50} \mathrm{G}(\mathrm{mg} / \mathrm{L})$ & $2.05[1.64,2.46]$ & $2.24[1.32,3.64]$ \\
\hline$E C_{50} \mathrm{~A}(\mathrm{mg} / \mathrm{L})$ & $0.96[0.78,1.14]$ & $1.10[0.63,1.82]$ \\
\hline $\mathrm{MTT}_{1}$ (hours) & $28.6[27.25,29.95]$ & $34.92[29.25,45.50]$ \\
\hline $\mathrm{MTT}_{2}$ (hours) & 118.30 & $64.86[1.43,140]$ \\
\hline Proportional residual error $\left(\varepsilon_{I N R}\right) \mathrm{CV} \%$ & 20.00 & $14.70[13.50,15.90]$ \\
\hline 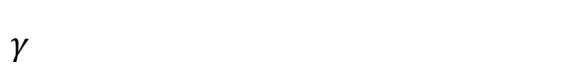 & $1.15[1.05,1.25]$ & $1.51[1.14,2.01]$ \\
\hline $\mathrm{BSV} E C_{50}(\mathrm{CV} \%)$ & $34[29.93,38.07]$ & $29.73[25.78,33.98]$ \\
\hline $\mathrm{BSV} K_{10}(\mathrm{CV} \%)$ & 58.90 & $63.24[35.29,97]$ \\
\hline BSV CL (CV \%) & $29.83[17.9,41.76]$ & $44.18[21.48,67.72]$ \\
\hline BSV V (CV \%) & $23.23[10.17,36.31]$ & $49.46[15.01,79.96]$ \\
\hline
\end{tabular}

$E C_{50} \mathrm{G}$ and $E C_{50} \mathrm{~A}$ concentration of s-warfarin at $50 \%$ of maximum drug effect for $\mathrm{G}$ and $\mathrm{A}$ allele, MTT mean 12 transit time, CV coefficient of variation, $\gamma$ Hill coefficient, BSV between subject variability, $K_{10}$ first-order 13 elimination rate constant, $\mathrm{CL}$ clearance, $\mathrm{V}$ volume of distribution of $s$-warfarin 


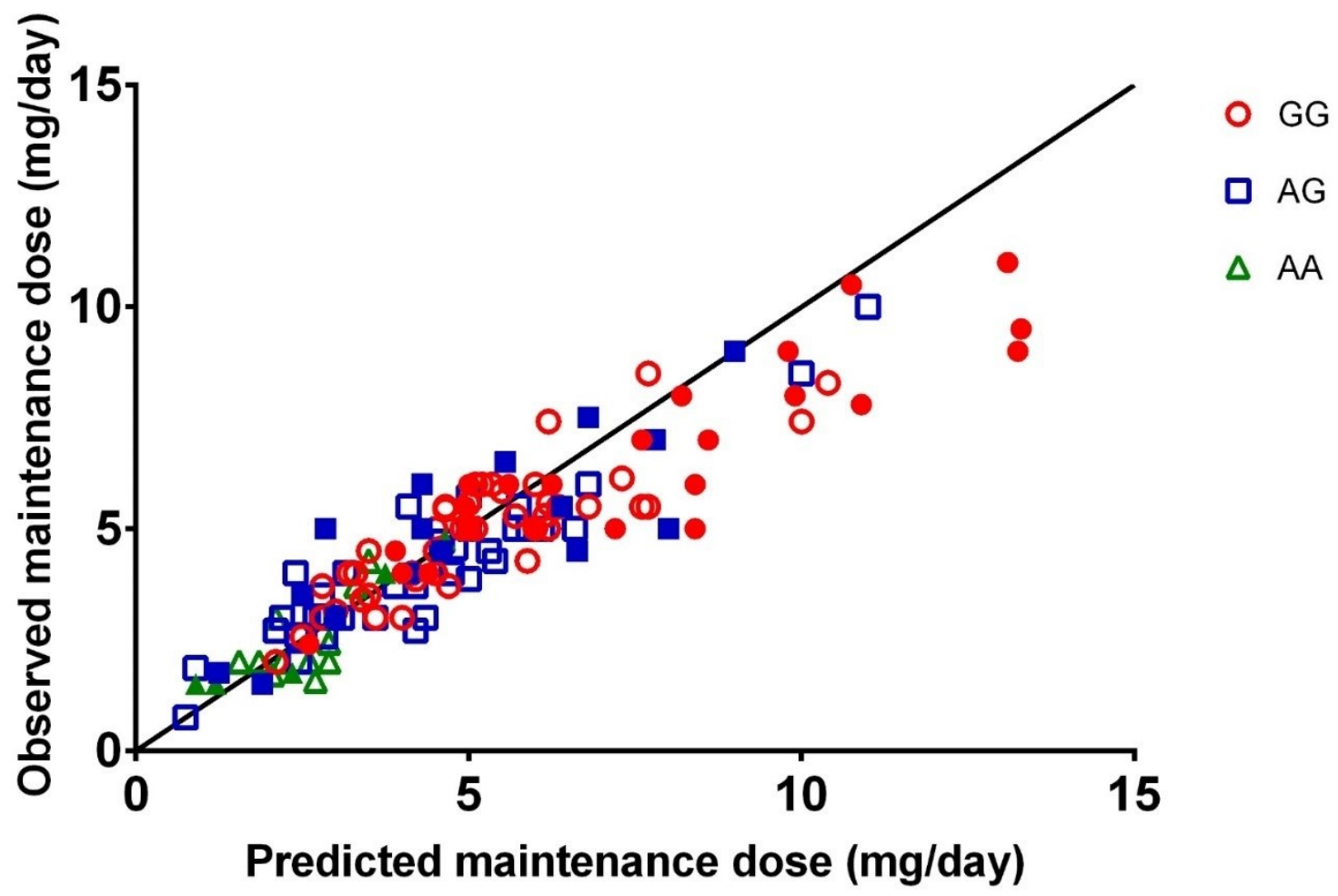

17

$18 \quad$ Figure 1 


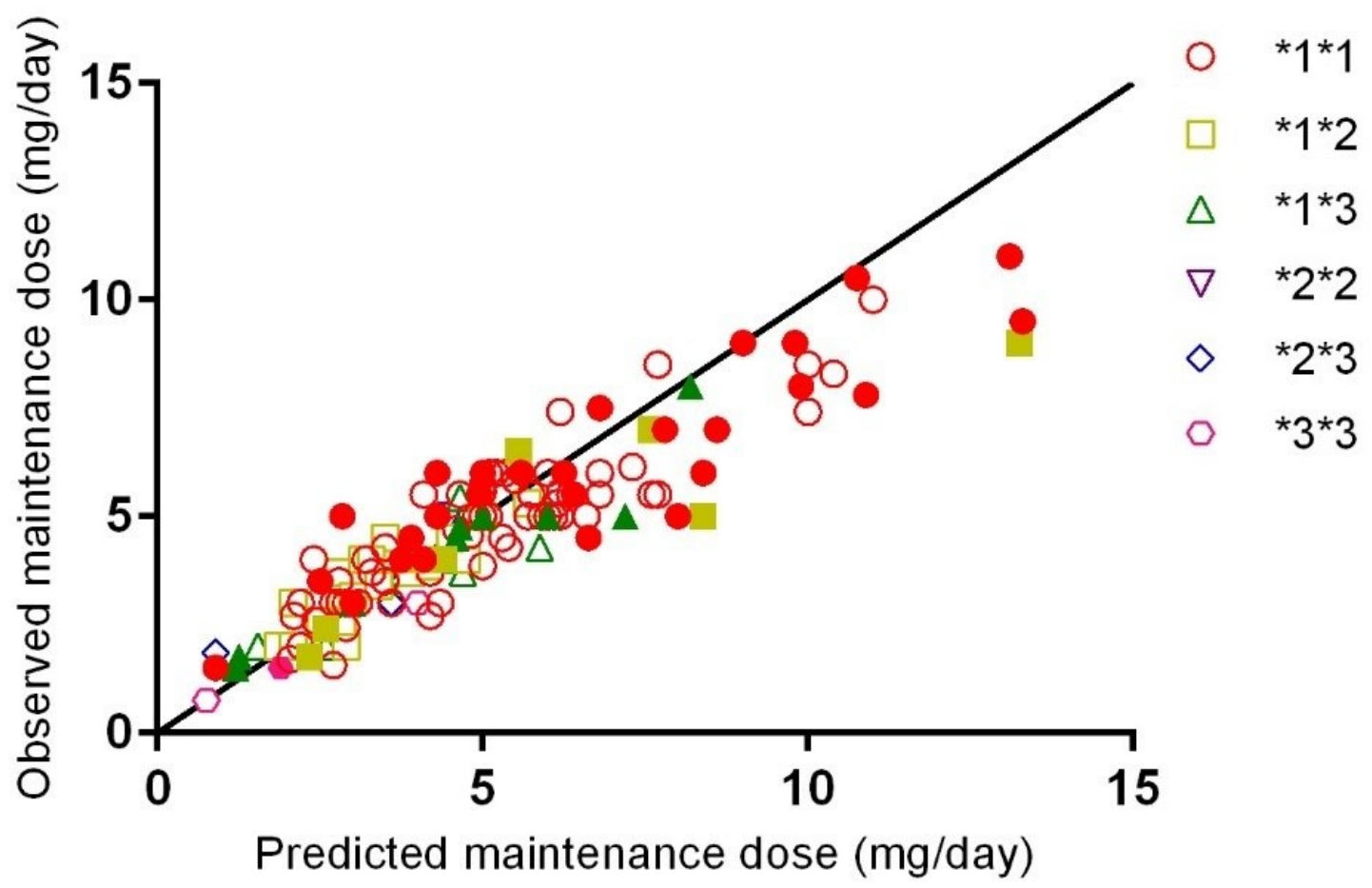

$20 \quad$ Figure 2 